\title{
Infective endocarditis with left to right intracardiac fistula due to Streptococcus anginosus - a rare complication caused by an even rarer bacterium
}

\author{
Robert Forster ${ }^{\mathrm{a}}$, Fernando Peixoto Ferraz de Campos $^{\mathrm{b}}$, Silvana Maria Lovisolo ${ }^{\mathrm{c}}$, \\ Vera Demarchi Aiello ${ }^{d}$, João Augusto dos Santos Martines ${ }^{e}$
}

Forster R, Campos FPF, Lovisolo SM, Aiello VD, Martines JAS. Infective endocarditis with left to right intracardiac fistula due to Streptococcus anginosus - a rare complication caused by an even rarer bacterium. Autopsy Case Rep [Internet]. 2013; 3(4): 13-22. http://dx.doi.org/10.4322/acr.2013.034

\section{ABSTRACT}

\begin{abstract}
Although infective endocarditis (IE) has been described in reports dating from the Renaissance, the diagnosis still challenges and the outcome often surprises. In the course of time, diagnostic criteria have been updated and validated to reduce misdiagnosis. Some risk factors and epidemiology have shown dynamic changes since degenerative valvular disease became more predominant in developed countries, and the mean age of the affected population increased. Despite streptococci have been being well known as etiologic agents, some groups, although rare, have been increasingly reported (e.g., Streptococcus milleri.) Intracardiac complications of IE are common and have a worse prognosis, frequently requiring surgical treatment. We report a case of a middle-aged diabetic man who presented with prolonged fever, weight loss, and ultimately severe dyspnea. IE was diagnosed based on a new valvular regurgitation murmur, a positive blood culture for Streptococcus anginosus, an echocardiographic finding of an aortic valve vegetation, fever, and pulmonary thromboembolism. Despite an appropriate antibiotic regimen, the patient died. Autopsy findings showed vegetation attached to a bicuspid aortic valve with an associated septal abscess and left ventricle and aortic root fistula connecting with the pulmonary artery. A large thrombus was adherent to the pulmonary artery trunk and a pulmonary septic thromboemboli were also identified.
\end{abstract}

Keywords: Endocarditis; Bicuspid Aortic Valve; Streptococcus anginosus; Aorta-pulmonary artery fistula; Pulmonary Embolism; Autopsy.

\section{CASE REPORT}

A 56-year-old male had a 2-month history of recurrent low-grade fever, occasional chills, cough, and progressive shortness of breath. He also described malaise and loss of appetite with an $8 \mathrm{~kg}$ weight loss over the 2 last months. A few days before presentation to the emergency unit, his temperature rose to $39{ }^{\circ} \mathrm{C}$ and he had shaking, chills, and diaphoresis. Dyspnea supervened. He had been

\footnotetext{
a Department of Internal Medicine - Hospital das Clínicas - Faculdade de Medicina - Universidade de São Paulo, São Paulo/SP - Brazil.

b Department of Internal Medicine - Hospital Universitário - Universidade de São Paulo, São Paulo/SP - Brazil.

${ }^{c}$ Anatomic Pathology Service - Hospital Universitário - Universidade de São Paulo, São Paulo/SP - Brazil.

d Laboratory of Pathology - Instituto do Coração - Hospital das Clínicas - Faculdade de Medicina - Universidade de São Paulo, São Paulo/SP - Brazil.

e Diagnostic Imaging Service - Hospital Universitário - Universidade de São Paulo, São Paulo/SP - Brazil.
}

Copyright $\odot 2013$ Autopsy and Case Reports - This is an Open Access article distributed of terms of the Creative Commons Attribution NonCommercial License (http://creativecommons.org/licenses/by/3.0/) which permits unrestricted non-commercial use, distribution, and reproduction in any medium provided article is properly cited. 
treated with a 7-day regimen of levofloxacin and antipyretics for a presumed diagnosis of pneumonia, and studies for tuberculosis were initiated. There was a mild and temporary relief of symptoms. Past medical history included hypertension, uncontrolled type II diabetes mellitus, asthma, and smoking. The patient was unaware of previous heart disease. Approximately 2 months before the onset of symptoms, the patient underwent dental root canal

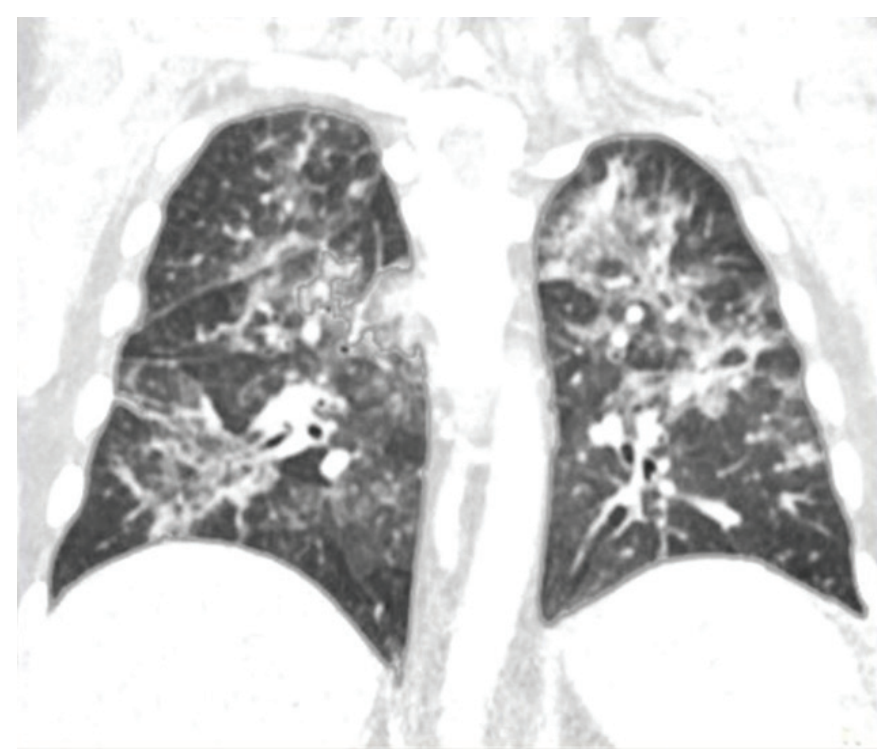

Figure 1 - Multidetector computed tomography (CT) of the thorax with coronal reconstruction showing diffuse bilateral ground-glass opacities, pulmonary parenchyma consolidation, and interlobular septa thickening. treatment. On admission showed an ill-appearing, obese (111.5 kg body weight) patient, was conscious and febrile $\left(39.5{ }^{\circ} \mathrm{C}\right.$ axillary temperature). Blood pressure was $140 / 60 \mathrm{mmHg}$, pulse 112 per minute, respiratory rate 44 per minute. With room air oxygen saturation was $69 \%$. Diffuse expiratory wheezing and bilateral rales were present. The remainder of the examination was unremarkable except for mild lower limb edema. Capillary glucose determination was $330 \mathrm{mg} / \mathrm{dL}$; other laboratory test results were unremarkable. Thoracic plain radiography demonstrated expressive pulmonary congestion and an apparently normal heart silhouette. The ECG showed sinus tachycardia without signs of ischemia, conduction block, or QRS axis deviation.

The diagnosis of sepsis due to pulmonary infection was made and treatment with ceftriaxone plus clarithromycin and non-invasive respiratory support was started. Episodes of sudden respiratory worsening ensued, and the appearance of a diastolic parasternal murmur was detected. On hospital day three, blood cultures grew Gram-positive cocci, subsequently identified as Streptococcus anginosus (microbial identification system VITEK® 2 Compact, bioMerieux). Doppler echocardiography showed enlarged left cardiac chambers, left ventricle hypertrophy, left ventricle ejection fraction of $71 \%$, and a thickened aortic valve with a vegetation as well as mild to moderate aortic insufficiency. Thoracic computed tomography (CT) showed diffuse and bilateral ground-glass

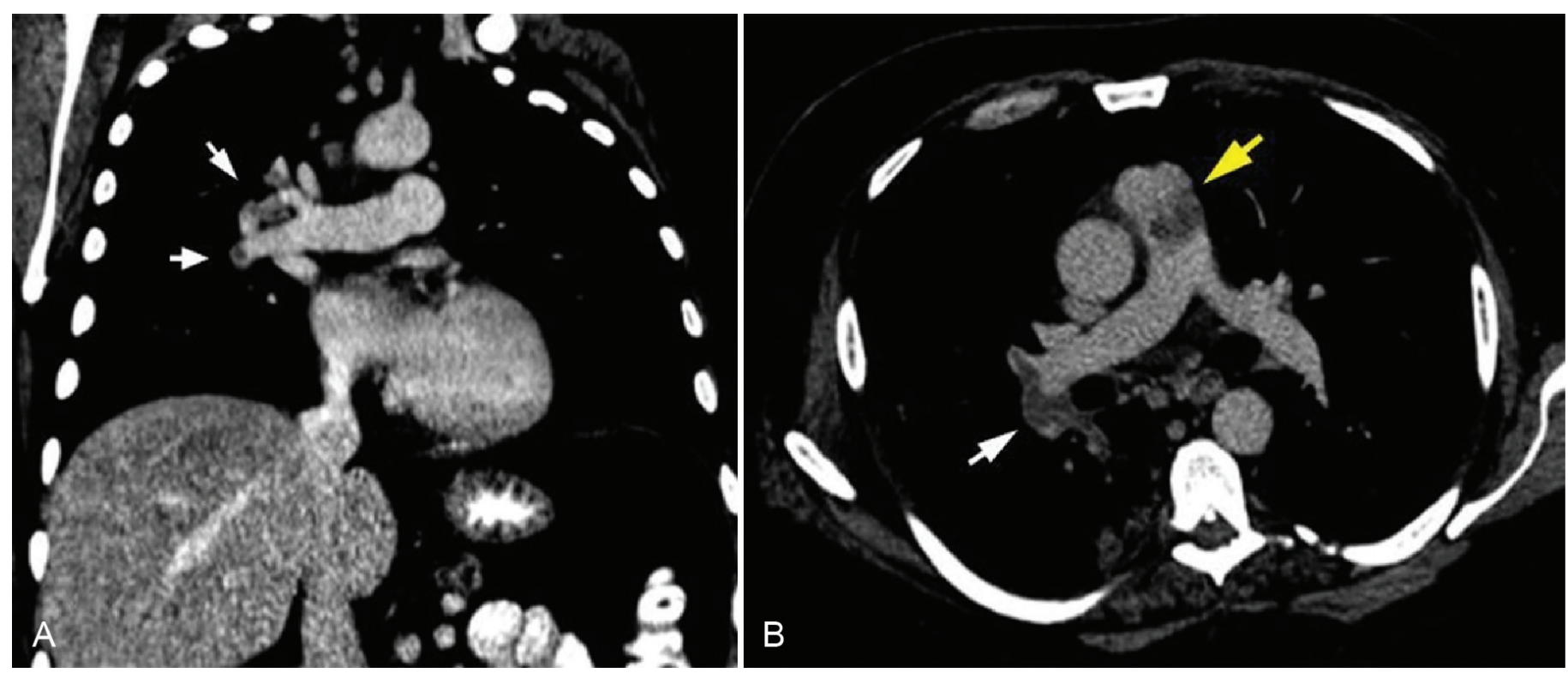

Figure 2 - Multidetector CT of the thorax. A - Coronal reformation. The presence of filling defects in the upper lobar and interlobar branches of the right pulmonary artery is evident (arrows); $\mathbf{B}$ - The axial plane showing filling defects in the trunk (yellow arrow) and right pulmonary artery branches (white arrow). 
opacity suggestive of pulmonary parenchyma consolidation with interlobular septa thickening (Figure 1). Laminar atelectasis in both lung bases and mediastinal lymphadenomegaly were present.

Intraluminal filling defects of the pulmonary artery trunk, and of the segmental and subsegmental branches of the right pulmonary artery were

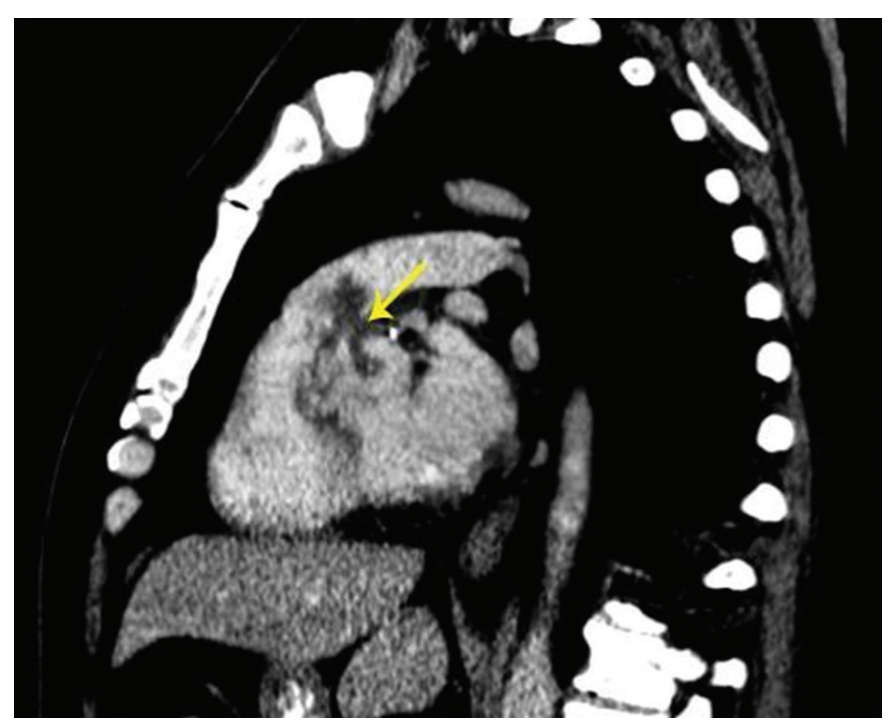

Figure 3 - Multidetector CT of the thorax, sagittal reformation, showing the intraluminal filling defect in the pulmonary artery trunk communicating with the aortic root (yellow arrow). detected (Figure 2). In the sagittal reconstruction, a filling defect communicating the aortic root and the pulmonary artery trunk was observed (Figure 3 ).

Abdominal imaging showed an enlarged spleen with peripheral wedge-shaped hypoenhancing images in the spleen indicative of multiple infarctions (Figure 4).

The antibiotic regimen was changed to penicillin and gentamycin, but the patient died soon after due to complete atrioventricular (AV) block followed by $\mathrm{AV}$ dissociation and asystole, unresponsive to advanced cardiovascular life support maneuvers.

\section{AUTOPSY FINDINGS}

The external examination was unremarkable except for obesity.

The brain weighed $1398 \mathrm{~g}$ (reference value (RV): $1400 \mathrm{~g}$ ) and showed an 8.0 long $\mathrm{cm}$ right temporo-parietal superficial hemorrhagic area, which, on section surface, was limited to the subdural space and meningeal surface.
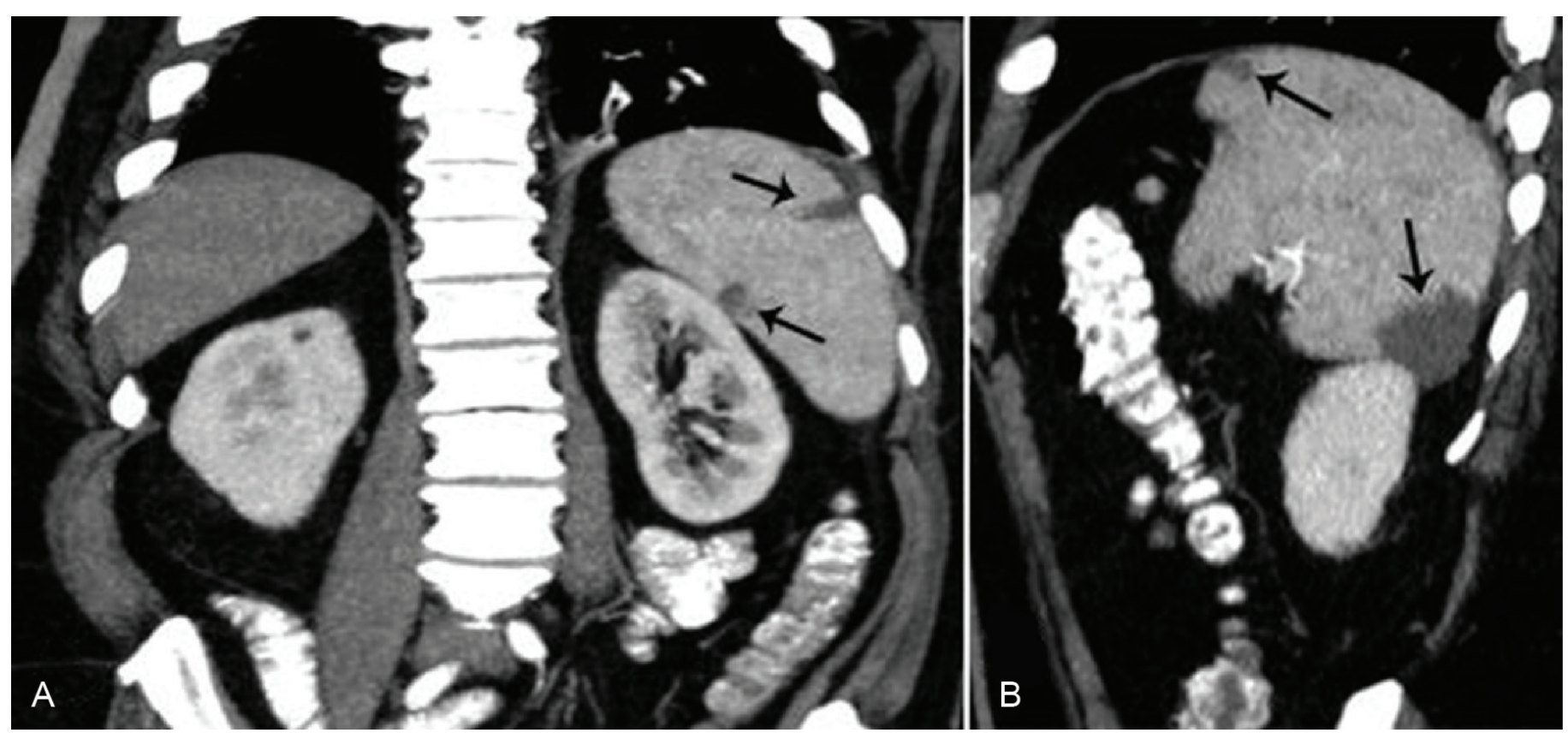

Figure 4-Multidetector CT of the abdomen. A and B - Coronal reformation showing multiple hypo-enhancing areas in the subcapsular splenic region (arrows), compatible with infarctions. 
Mild bilateral pleural serosanguineous effusion was present. The lungs were congested with increased volume and weight. The right lung weighed $1240 \mathrm{~g}$ (RV: $350-450 \mathrm{~g})$ and the left weighed $927 \mathrm{~g}$ (RV: 250-350 g). A subpleural peripheral yellowish wedge-shaped infarct was present in the right lung, confirmed microscopically to be an ischemic infarction with pulmonary parenchyma necrosis (Figures 5A and 5B). Multiple thromboemboli of segmental branches were present in the pulmonary artery system (Figure $5 \mathrm{C}$ ). Both the infarction and the thrombi showed Gram-positive cocci (BrownHopps modified Gram method) (Figure 5D). Many alveolar spaces were filled with polymorphonuclear leukocytes and fibrin and surrounded by areas of organization as well as pulmonary edema.

The heart weighed $477 \mathrm{~g}$ (RV: 350g). A firm white $1.5 \mathrm{~cm}$ yellow and friable vegetation was attached to a bicuspid aortic valve (Figures 6B and 7A) with an adjacent septal abscess, a subvalvar opening orifice in the left ventricle and a cleftshaped fistula connecting the aortic root with the right posterior sinus of the pulmonary valve and the pulmonary artery trunk were found (Figures $6 \mathrm{~A}$ and $6 \mathrm{D} ; 8 \mathrm{~A}$ and $8 \mathrm{~B}, 9 \mathrm{~A}$ and $9 \mathrm{~B}$ ). The left-to-right heart fistulous path was partially obliterated by a large 3.0 $\mathrm{cm}$ thrombus adherent to the pulmonary valve cusp (Figures $6 \mathrm{~A}$ and $\mathrm{C}$ ). The histologic examination of the aortic valve vegetation (Figures $7 \mathrm{~B}$ and $7 \mathrm{C}$ ) and the thrombus into the pulmonary valve cusp showed many Gram-positive cocci (Figure 7D).

The spleen was greatly enlarged (721 g; RV: $150 \mathrm{~g}$ ), and was soft with scattered small, yellowish nodules throughout the parenchyma and a larger area of necrosis, The liver was congested and weighed $2880 \mathrm{~g}$ (RV: $1500 \mathrm{~g}$ ). On microscopy, congestion and moderate macrovesicular steatosis were observed. Both kidneys were enlarged, and showed acute tubular necrosis. The remaining organs and tissues did not have significant alterations.
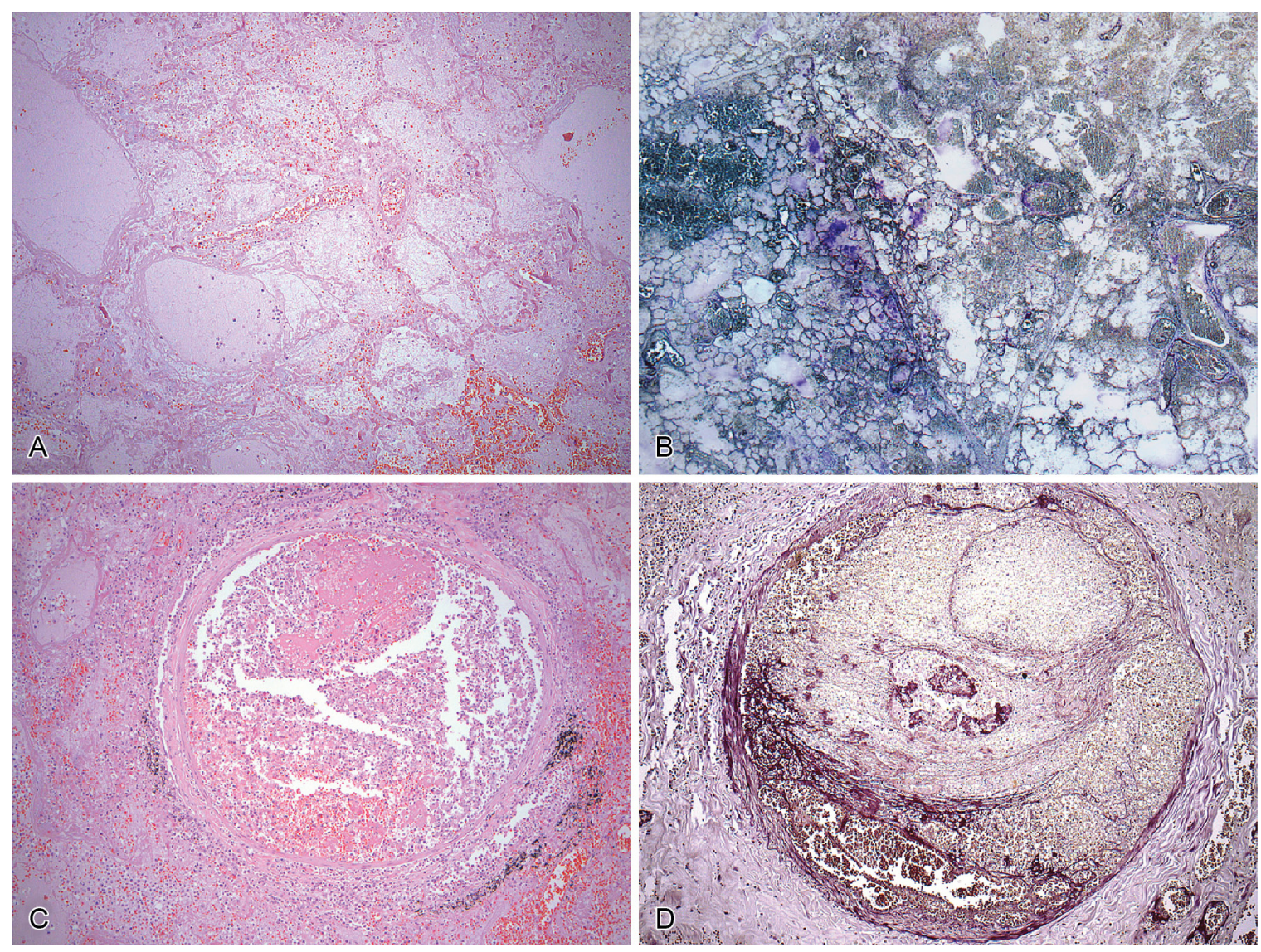

Figure 5-Photomicrography of the lung. A - Ischemic infarction with necrosis of the pulmonary parenchyma (HE, 10X); $\mathbf{B}-$ The ischemic area of the lung with evidence of Gram-positive cocci by Brown-Hopps staining $(\mathrm{BH}, 4 \mathrm{X})$; $\mathbf{C}$ - Thromboembolism of the pulmonary artery subsegmental branches (HE, 10X); D - The presence of Gram-positive cocci into the thrombosed pulmonary blood vessels (BH, 10X). 

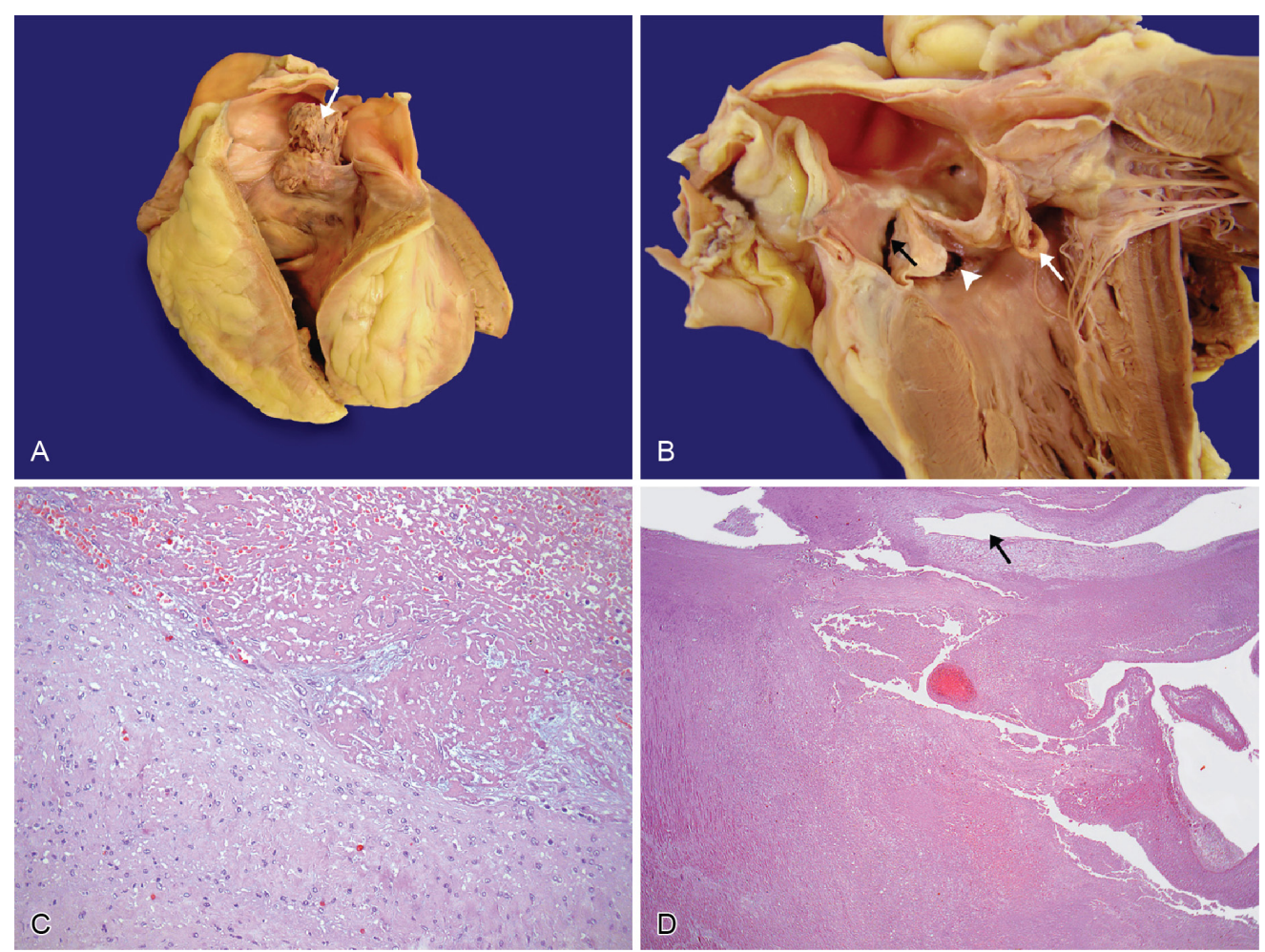

Figure 6 - Gross view of the opened right (A) and left (B) ventricular outflow tracts A shows a large $3.0 \mathrm{~cm}$ thrombus filling the right posterior sinus of the pulmonary valve, partially obliterating the left-to-right heart fistulous path (white arrow); In B note the vegetation on the distorted but originally bicuspid aortic valve (white arrow), the cleft-shaped organizing fistula connecting the aortic root with the pulmonary valve (black arrow), and the orifice of the fistula opening in the left ventricle, below the valve (arrow head); $\mathbf{C}$ - Photomicrography of the organizing pulmonary valve cusp thrombus with granulation tissue (HE, 20X); D - Photomicrography of the cleft-shaped organizing fistula (black arrow) (HE, 4X).
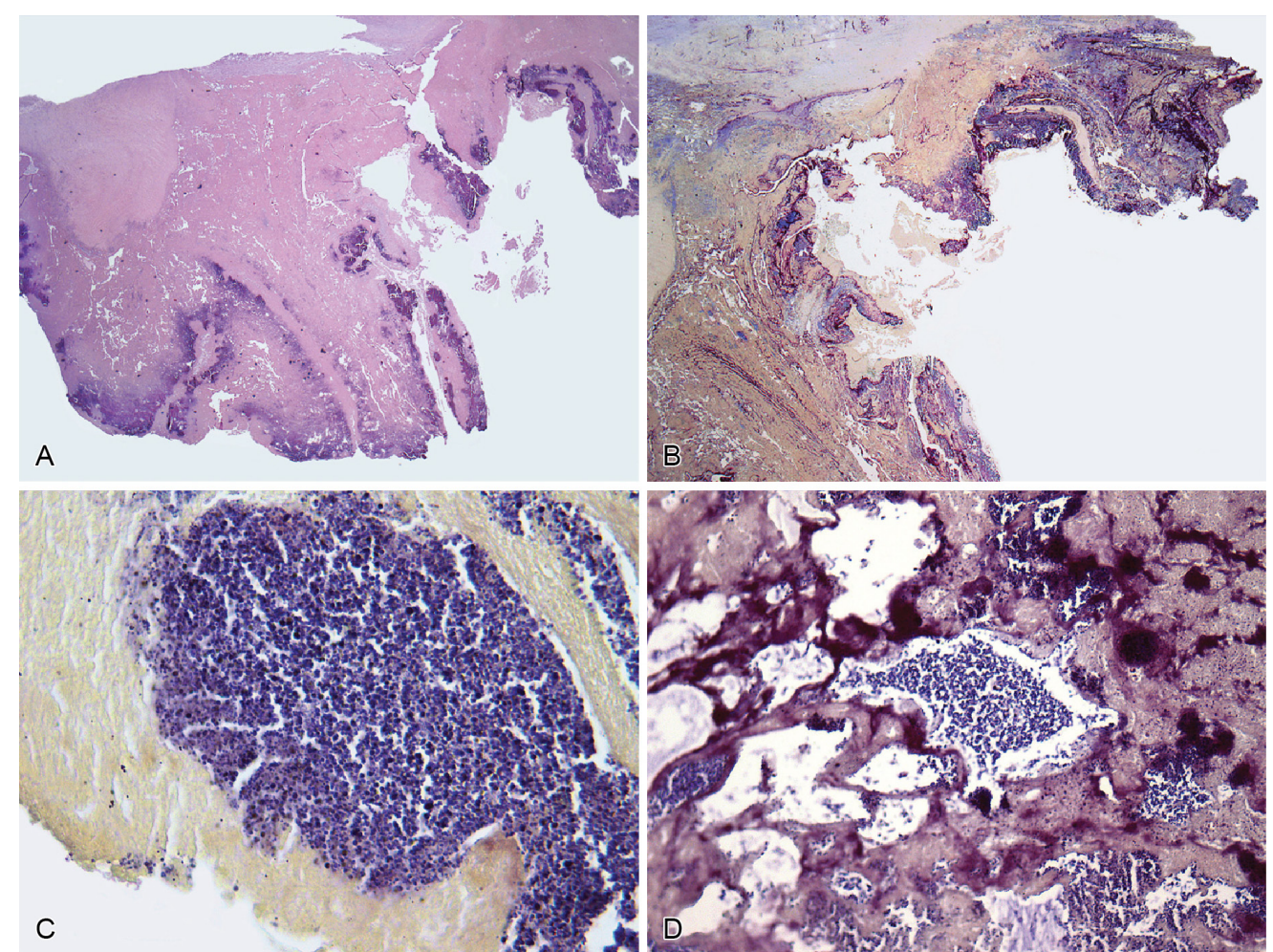

Figure 7 - A - Photomicrography of the aortic valve vegetation (HE, 1.25X); $\mathbf{B}$ and $\mathbf{C}$ - The presence of Gram-positive cocci by Brown-Hopps staining $(\mathrm{BH}, 1.25 \mathrm{X}$, in $\mathrm{B})(\mathrm{BH}, 40 \mathrm{X}$ in $\mathrm{C})$; $\mathbf{D}$ - Photomicrography of the pulmonary valve cusp thrombus with Gram-positive cocci (BH, 20X). 

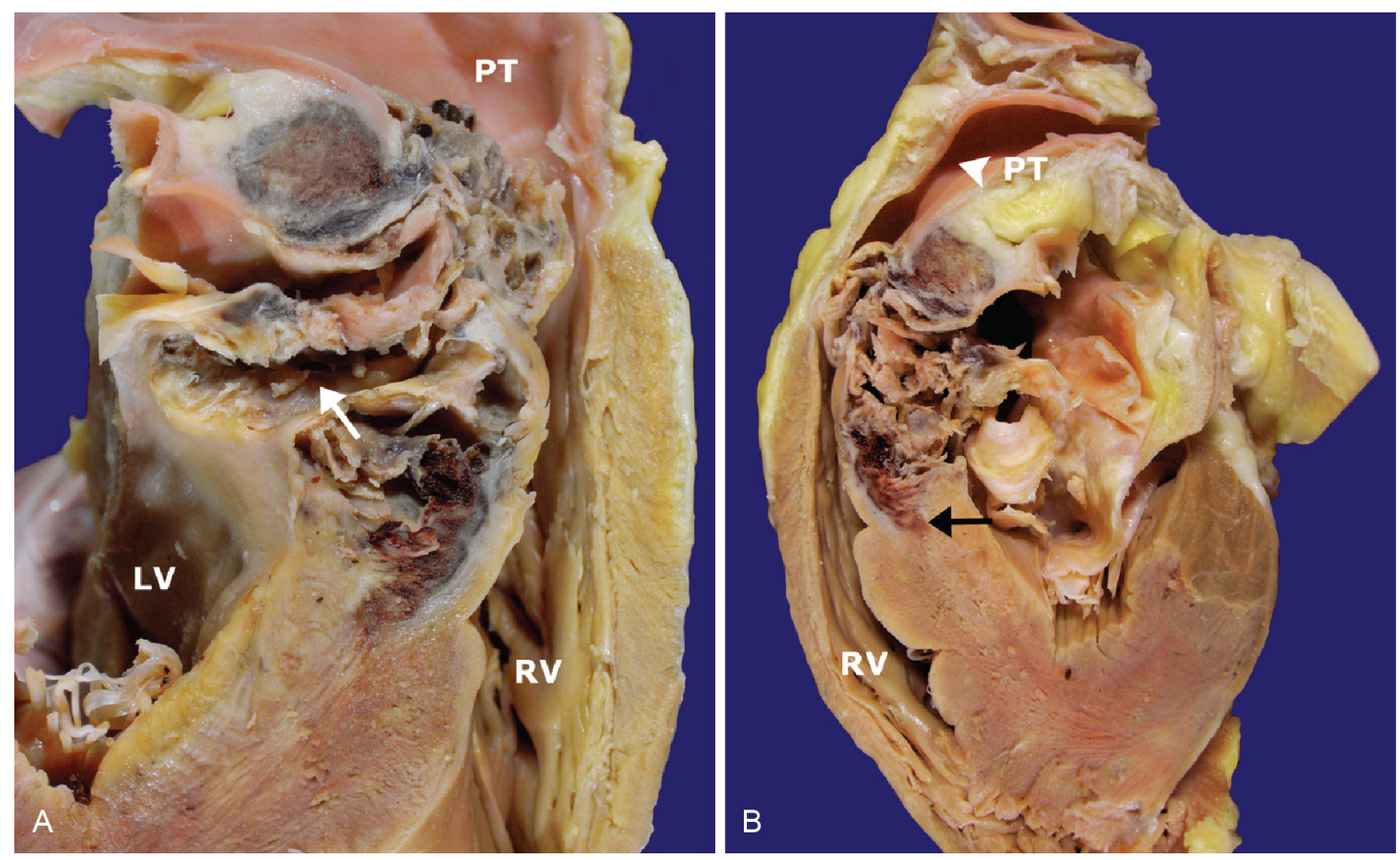

Figure 8 - Gross view of the longitudinal cross-section of the heart through the right ventricular outflow tract. Panels A and B are complementary sections. Compare with the sagittal section obtained on CT (Figure 3); Note the huge abscess of the aortic valve and aortic root extending to the ventricular septum forming a cleft-shaped organizing fistula (white arrow). The septal abscess extends into the left ventricular wall (black arrow) and protrudes below the pulmonary valve. The left ventricular wall is hypertrophic $(2,9 \mathrm{~cm})$. RV- right ventricle, LV- left ventricle, PT- pulmonary trunk.
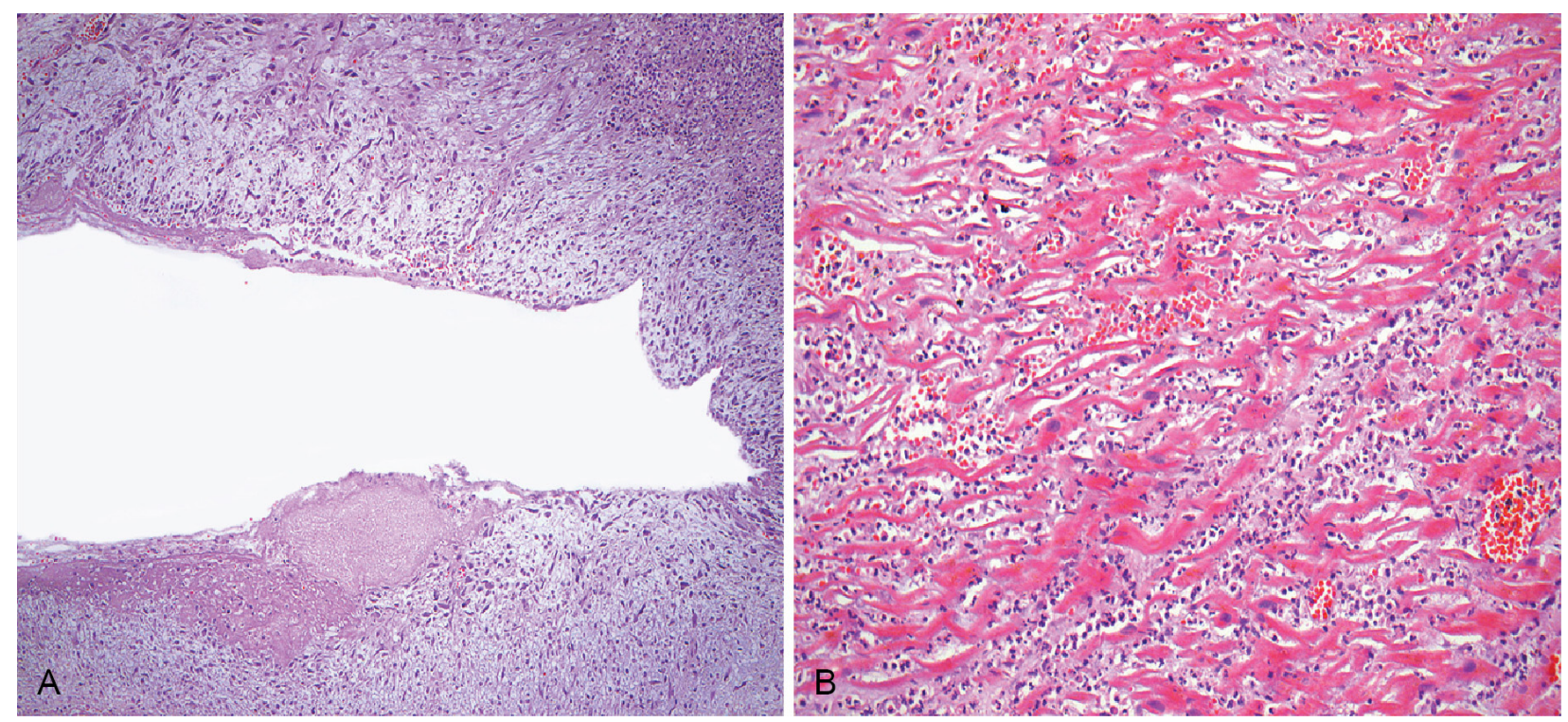

Figure 9 - A - Photomicrography of the cleft-shaped organizing fistula with granulation tissue (HE, 10X); B - Photomicrography of the abscess extending into the left ventricle (myocardium fibers intermingled with neutrophils) (HE, 20X).

\section{DISCUSSION}

Endocarditis has been known since the autopsy findings of Lazare Rivière, a professor at Montpellier University (1589-1655). William Senhouse Kirkes in 1852 described a cerebral embolism associated with IE. ${ }^{1}$ However, the first comprehensive discussion of IE was in 1885 when
Sir William Osler gave the Gulstonian Lecture, calling the entity "malignant endocarditis."

Due to its variable clinical presentation, the diagnosis of $\mathrm{IE}$ often requires a high index of suspicion. Over time, diagnostic criteria have been validated and updated. In 1994, investigators at Duke University (Durham, NC, USA) modified the previously used von Reyn criteria to include 
echocardiography data and intravenous drug abusers. $^{3}$ The "Duke criteria," are now widely used for diagnosis. More recently, it received the amendment of positive serology for Q-fever among the major criterion. ${ }^{4}$

The incidence of IE is steadily increasing, affecting as many as 12.7 persons per 100,000 per year. The mean age is 60.8 years. The most important risk factors include prosthetic heart valves, intracardiac devices, congenital heart disease, valvular heart disease, and a previous history of IE. While degenerative valve disease, prosthetic valves, and invasive procedures became the most frequent predisposing factors for IE in developed countries, rheumatic valvular disease still remains the predominant factor in developing countries. ${ }^{5,6}$ Other risk factors include hemodialysis, and coexisting conditions, such as diabetes mellitus, HIV infection, and intravenous drug use..$^{7,8}$ Diabetes mellitus is not only associated with the increased prevalence of non-rheumatic aortic valve disease, and therefore constitutes a risk factor for IE development, but also is associated with a worse clinical course and outcome..$^{9,10}$ In one institutional series of native valve endocarditis, bicuspid aortic valve (BAV) was the most important cardiac predisposing factor for IE. ${ }^{11}$ BAV was detected at autopsy in our patient and represents a frequent congenital heart anomaly, affecting $1-2 \%$ of the population. ${ }^{12,13}$ It may be inherited in an autosomal dominant pattern occurring sporadically and is not only associated with aortic stenosis or regurgitation, but also represents an important risk factor for IE.

Streptococci are the second most frequently involved etiological agents in IE, which are only surpassed by Staphylococcus aureus. ${ }^{5}$ In our case, the isolated pathogen was $S$. anginosus, which belongs to the Streptococcus milleri ( $S$. milleri) group. ${ }^{14}$ Despite their close phylogenetic relationships with the other viridans streptococci, the clinical disease spectrum caused by members of the $S$. milleri group is different from that caused by other viridans streptococci, since they are more prone to abscess formation. ${ }^{15}$ In 1984, revising the nomenclature, Facklan ${ }^{16}$ divided the group of $S$. milleri into three species: $S$. intermedius, $S$. constellatus, and $S$. anginosus. The latter pertains to Lancefield groups F, A, C, and G, and the existence of some ungroupable strains. ${ }^{17} \mathrm{~S}$. milleri is considered a part of the resident flora of the oral cavity and upper respiratory tract. The gastrointestinal tract and urogenital system may also harbor these bacteria but are less commonly colonized. In the mouth, S. milleri seems to have predilection for the gingival crevice and the fitting surface of dentures; therefore, it is associated with periodontal diseases such as gingivitis, periodontitis, and odontogenic abscesses. The latter was probably the source of the bacteremia in our case.

Transient bacteremia is common and unsuspected in many cases and may follow vigorous tooth brushing. S. milleri bacteremia has been frequently documented after dental extraction or manipulation. Our patient undrewent a root canal treatment, which was most probably the triggering event. IE by S. milleri is infrequent, compared with other streptococci, and accounts for $4-15 \%$ of the cases of $\alpha$-hemolytic streptococcal endocarditis. ${ }^{17}$ S. milleri has been previously implicated in cases of myocardial abscess associated with endocarditis. ${ }^{18,19}$ In a series of six cases of S. milleri endocarditis, all were caused by $S$. anginosus. ${ }^{20}$ Of the $S$. milleri group, $S$. anginosus seems to be the most frequently implicated as being the causative agent of IE. ${ }^{21}$ Bacteremia also follows invasion of portal circulation by intestinal flora, often, in older inidividuals, by transient, subclinical intestinal ischemia.

Normal endothelium of the heart and its valves are resistant to colonization and infection by circulating bacteria. This is supported by the high frequency of bacteremia as opposed to the relatively Iow frequency of IE. As a reminder, bacteremia can occur not only as a result of invasive procedures, but also after daily events, such as chewing or tooth brushing. Endothelial disruption due to factors such as turbulent blood flow, inflammation, degenerative changes, or catheters and electrodes, can expose the tissue matrix, leading to platelet adherence and fibrin deposition. The resultant micro ulcers and micro thrombi predispose to bacterial adherence and infection. ${ }^{22}$ In our patient, the bicuspid valve and consequent abnormal leaflet function and motion likely led to turbulent blood flow and fibrin deposition which then served as a nidus for secondary infection.

Fever and malaise are the most frequent sign and symptom of native-valve endocarditis. In a series of 50 patients with bicuspid valve endocarditis, the next most frequent sign was the presence of a heart murmur ( $60 \%$ of cases), which was regurgitant in $50 \%$ of cases. Other frequent symptoms/signs were night-sweats and weight loss, which occurred in more than one-quarter of patients. Dyspnea occurred in $36 \%$ of cases, a change in mentation in $22 \%$, and anorexia in $18 \%$. 
More than $10 \%$ of patients had myalgia, dry cough, diarrhea or vomiting, splenomegaly, chest pain, a non-specific vascular phenomena-such as rashes, splinters, or petechiae-arthralgia, and/or chills. ${ }^{11}$ Our patient presented with weight loss, dyspnea, anorexia, myalgia, dry cough, and chills. The lack of specificity of these symptoms may explain the delayed diagnosis. A high degree of suspicion for IE is warranted in febrile illnesses with non-specific symptoms.

IE is associated with many non-cardiac as well as cardiac complications. Non-cardiac complications include neurologic complications occurring in $20-40 \%$ of IE patients, septic emboli, mycotic aneurysms, immune complex related vascular damage, such as in glomerulonephritis and splenic abscess. ${ }^{22}$ Cardiac complications are represented by hemodynamic disturbance due to valve dysfunction and/or myocardial abscess, which may result in fistula development with or without conduction abnormalities. In a series of 238 patients, more than $50 \%$ suffered from one complication, $25 \%$ suffered from two complications, and approximately $8 \%$ suffered from three or more complications. ${ }^{23}$ Although patients with a bicuspid aortic valve may be completely asymptomatic, the association of this condition with aortic stenosis, aortic regurgitation, and IE has been known for almost 150 years. ${ }^{12,24}$ Clinical diagnosis of this condition was unsatisfactory before the widespread use of cross-sectional echocardiography, approximately 25 years ago, ${ }^{12}$ but it may still pose a diagnostic challenge. In a series of cases over a 30year span, echocardiograms that were performed preoperatively showed a sensitivity as low as 35\% for BAV. This rate is improving with modern echoimaging techniques. ${ }^{11}$ Aortic valve endocarditis can be complicated by periannular extension and abscess formation. ${ }^{25}$ which as many as $50 \%$ of cases. ${ }^{11,26}$ Increasing patient age and fistulization of the abscess have been previously found to be independent risk factors in both 1-month mortality and overall operative mortality. ${ }^{27}$

Aortic perivalvular abscesses are associated with first-, second-, and third-degree heart block. High-grade AV block occurred in $10 \%$ of cases of IE in a series of aortic perivalvular abscess. ${ }^{27}$ Additionally, in a large cohort of patients with native aortic valve IE (bicuspid or tricuspid) with perivalvular complications, aorto-cavitary fistula formation was associated with a higher incidence of third-degree heart block ( $11 \%$ vs. $4 \%, p=0.07$ ) and moderate to severe heart failure $(67 \%$ vs. $52 \%$, $p=0.07)$ compared with unruptured periannular abscess cases. ${ }^{28}$ In the present case, complete AV block developed as a final event, suggesting that the abscess, until that stage, had not involved the conduction system.

Myocardial abscess is a potential complication of IE and may develop as a consequence a perivalvular infection or as a result of septic coronary emboli. Similar to fistula formation, it represents a class I, level B indication for urgent surgical intervention. ${ }^{22}$

An aorto-pulmonary fistula in left-sided IE due to $S$. aureus in a HIV-positive patient and IV drug user was previously reported. ${ }^{29}$ Septal myocardial abscess leading to later rupture and formation of a fistula to the pulmonary artery, was described in a 12-month-old child after surgical drainage of a leg abscess. $S$. aureus was isolated in blood cultures. ${ }^{30}$

To the best of our knowledge this is the first case report of a fistula involving the left ventricle, aorta, and the pulmonary artery due to $S$. anginosus IE in an adult patient. In our patient, the perivalvar and interventricular abscess and the fistula connected to the pulmonary trunk was somewhat capped by the pulmonary thrombus. The rapid clinical deterioration, manifested as respiratory insufficiency, was most likely due to the opening of the fistula into the pulmonary artery tree, with consequent overflow and pulmonary edema. Moreover, the giant thrombus attached to the endothelial surface of the pulmonary trunk was the source of subsequent septic embolization to the lungs, which worsened the clinical picture.

\section{CONCLUSION}

Unfortunately, the diagnosis of IE was missed at the very beginning of this case when specific antibiotics might have prevented this disastrous outcome. The diagnosis of IE often requires a high index of suspicion. A prolonged history of fever and weight loss in a diabetic patient should strongly suggest IE and all efforts should be made to establish the diagnosis. The history of a recent dental procedure certainly should have raised the possibility of IE. Autopsy findings clarified the pathophysiology of this case, and provided further emphasis for the importance of autopsy in the modern era. We should recall the words of William Osler, the father of modern medicine: "Listen to your patient, he is telling you the diagnosis." 


\section{REFERENCES}

1. Pearce JMS. Cerebral embolism in endocarditis: William Senhouse Kirkes (1823-64). J Neurol Neurosurg Psychiatry. 2003;74:1570. http://dx.doi.org/10.1136/jnnp.74.11.1570

2. Osler W. The Gulstonian Lectures, on Malignant Endocarditis. Br Med J. 1885;1:467-70. http://dx.doi.org/10.1136/ bmj.1.1262.467

3. Durack DT, Lukes AS, Bright DK. New criteria for diagnosis of infective endocarditis: utilization of specific echocardiographic findings. Duke Endocarditis Service. Am J Med. 1994;96:2009. http://dx.doi.org/10.1016/0002-9343(94)90143-0

4. Li J, Sexton DJ, Mick N, et al. Proposed modifications to the Duke criteria for the diagnosis of infective endocarditis. Clin Infect Dis. 2000; 30:633-8. PMid:10770721. http://dx.doi. org/10.1086/313753

5. Bor DH, Woolhandler S, Nardin R, Brusch J, Himmelstein DU. Infective endocarditis in the US. 1998-2009: a nationwide study. PLoS One. 2013;8:e60033. PMid:23527296 PMCid:PMC3603929. http://dx.doi.org/10.1371/journal. pone.0060033

6. Fedeli U, Schievano E, Buonfrate D, Pellizzer G, Spolaore P. Increasing incidence and mortality of infective endocarditis: a population-based study through a record-linkage system. BMC Infect Dis. 2011;11:48-54. PMid:21345185 PMCid:PMC3051911. http://dx.doi.org/10.1186/1471-2334$11-48$

7. Correa de Sa DD, Tleyjeh IM, Anavekar NS, et al. Epidemiological trends of infective endocarditis: a populationbased study in Olmsted County, Minnesota. Mayo Clin Proc. 2010;85:422-6. PMid:20435834 PMCid:PMC2861970. http:// dx.doi.org/10.4065/mcp.2009.0585

8. Nesseler N, Launey Y, Mallédant Y. Infective endocarditis. N Engl J Med. 2013;369:784-5. PMid:23964952. http://dx.doi. org/10.1056/NEJMc1307282

9. Movahed MR, Hashenzadeh M, Jamal MM. Significant increase in the prevalence of non-rheumatic aortic valve disease in patients with type 2 diabetes mellitus. Exp Clin Endocrinol Diabetes. 2007;115:105-7. PMid:17318769. http://dx.doi.org/10.1055/s-2007-949656

10. Chirillo F, Bacchion F, Pedrocco A, et al. Infective endocarditis in patients with diabetes mellitus. J Heart Valve Dis. 2010;19:312-20. PMid:20583393.

11. Lamas CC, Eykyn SJ. Bicuspid aortic valve: a silent danger: analysis of 50 cases of infective endocarditis. Clin Infect Dis. 2000;30:336-341. PMid:10671338. http://dx.doi. org/10.1086/313646
12. Ward C. Clinical significance of the bicuspid aortic valve. Heart. 2000;83:81-5. http://dx.doi.org/10.1136/heart.83.1.81

13. Baumgartner H, Dabritz S. Congenital heart disease in adulthood. Med Klin (Munich). 2008;103:135-42.

14. Gray T. Streptococcus anginosus Group: clinical significance of an important group of pathogens. Clin Microbiol Newsl. 2005;27:155-9. PMid:18344063. http://dx.doi.org/10.1007/ s00063-008-1020-4

15. Lefort A, Lortholary $\mathrm{O}$, Casassus $\mathrm{P}$, et al. Comparison between adult endocarditis due to beta-hemolytic streptococci (serogroups A, B, C, and G) and Streptococcus milleri: a multicenter study in France. Arch Intern Med. 2002;162:24506. http://dx.doi.org/10.1016/j.clinmicnews.2005.09.006

16. Facklan RR. The major differences in the American and British Streptococcus taxonomy schemes with special reference to Streptococcus milleri. Eur J Clin Microbiol. 1984;3:91-3. http://dx.doi.org/10.1001/archinte.162.21.2450

17. Whitworth JM. Lancefield group $F$ and related streptococci. J Med Microbiol. 1990;33:135-51. http://dx.doi.org/10.1007/ BF02014323

18. Levandowski RA. Streptococcus milleri endocarditis complicated by myocardial abscess. South Med J. 1985;78:892-3. http://dx.doi.org/10.1099/00222615-33-3-135

19. Wallis DE, Venezio FR, Montoya A, Cook FV, Scanlon PJ. Streptococcus MG-intermedius endocarditis. South Med J. 1986;79:1313-4. http://dx.doi.org/10.1097/00007611198507000-00034

20. Woo PCY, Tse H, Chan K, et al. "Streptococcus milleri" endocarditis caused by Streptococcus anginosus. Diagn Microbiol Infect Dis. 2004;48:81-8. http://dx.doi. org/10.1097/00007611-198610000-00034

21. Kitada K, Inoue M, Kitano M. Experimental endocarditis induction and platelet aggregation by Streptococcus anginosus, Streptococcus constelatus and Streptococcus intermedius. FEMS Immunol Med Microbiol. 1997;19:2532. PMid:14972375. http://dx.doi.org/10.1016/j. diagmicrobio.2003.09.011

22. Habib G, Hoen B, Tornos P, et al. Guidelines on the prevention, diagnosis, and treatment of infective endocarditis (new version 2009). Eur Heart J. 2009, 30:2369-413. http:// dx.doi.org/10.1111/j.1574-695X.1997.tb01069.x

23. Mansur AJ, Grimberg M, Da Luz PL, Bellotti G. The complications of infective endocarditis. A reappraisal in the 1980s. Arch Intern Med.1992;152:2428-32. PMid:19713420. http://dx.doi.org/10.1093/eurheartj/ehp285

24. Kahveci G, Bayrak F, Pala S, Mutlu B. Impact of bicuspid aortic valve on complications and death in infective endocarditis of native aortic valves. Tex Heart Inst J. 2009;36:111-6. http://dx.doi.org/10.1001/archinte.1992.00400240050008 
25. Omari B, Shapiro S, Ginzton L, et al. Predictive risk factors for periannular extension of native valve endocarditis. Clinical and echocardiographic analyses. Chest. 1989;96:1273-9. PMid:19436803 PMCid:PMC2676612.

26. Tribouilloy C, Rusinaru D, Sorel C. Clinical characteristics and outcome of infective endocarditis in adults with bicuspid aortic valves : a multicentre observational study. Heart. 2010;96:1723-9.

27. Choussat R, Thomas D, Isnard R, et al. Perivalvular abscesses associated with endocarditis: clinical features and prognostic factors of overall survival in a series of 233 cases: Perivalvular Abscesses French Multicentre Study. Eur Heart J. 1999;20:232-41. PMid:20478858. http://dx.doi. org/10.1136/hrt.2009.189050

\section{Conflict of interest: None}

Submitted on: $30^{\text {th }}$ October 2013

Accept on: $7^{\text {th }}$ December 2013

Correspondence: Departamento de Clínica Médica

Hospital das Clínicas

Faculdade de Medicina da USP

Av. Enéas Carvalho de Aguiar, 155 - São Paulo/SP - Brazil CEP: 05403-000 - Phone: +55 (11) 3069-6412

E-mail: robertforster.ufrj@gmail.com
28. Anguera I, Miro JM, Evangelista A, et al. Periannular complications in infective endocarditis involving native aortic valves. Am J Cardiol. 2006;98:1254-60. http://dx.doi. org/10.1053/euhj.1998.1240

29. Obón Azuara B, Zalba Etayo B, Gutiérrez Cía I, Villanueva Anadón B. [Aorto pulmonary fistula: left-sided infective endocarditis in HIV and intravenous drugs abuser patient. Review of the literature]. An Med Interna. 2007;24:54750. Spanish. PMid:17056342. http://dx.doi.org/10.1016/j. amjcard.2006.06.016

30. Hershenson JA, Baker PB, Rowland DG. Ruptured Myocardial Abscess Causing Left Ventricle to Pulmonary Artery Communication in an Infant With Community-Associated Methicillin-Resistant Staphylococcus aureus Endocarditis. Arch Path Lab Med. 2011;135:1057-60. PMid:21810000. http://dx.doi.org/10.5858/2010-0144-CRR1 